\title{
Regional cerebral blood flow in patients with Parkinson's disease under chronic levodopa therapy: measurements during "on" and "off" response fluctuations
}

\author{
ELDAD MELAMED, MORDECHAI GLOBUS, BRACHA MILDWORF \\ From the Laboratory for Cerebrovascular Research and the Laboratory for Clinical Neurochemistry, \\ Department of Neurology, Hadassah University Hospital, Jerusalem, Israel
}

SUMMARY In ten Parkinsonians who developed dose-related response fluctuations under long-term levodopa therapy, regional cerebral blood flow (rCBF) and plasma levodopa levels were measured simultaneously, once during an "off" phase and again at an "on" stage of clinical benefit induced by a single oral dose of levodopa. Although plasma levodopa increased threefold during the "on" period, rCBF and the degree of its reduction from normal age-matched control values remained unchanged and similar to those in the "off" phase. Study suggests that the rCBF decreases in Parkinson's disease are unaffected by levodopa and are not due to deficient dopaminergic neurotransmission in the brain.

The regional cerebral blood flow (rCBF) is reduced in patients with Parkinson's disease ${ }^{12}$ but the causes are undetermined. Dopaminergic neurons or circulating dopamine may be involved in the regulation of the rCBF and several studies, ${ }^{34}$ although not all, ${ }^{5}$ suggest that dopaminergic stimulation induces cerebral vasodilation. Disruption of central dopaminergic pathways may also cause reduction of local cerebral metabolic rates. ${ }^{6}$ Therefore, the deficient nigrostriatal and also nigromesocortical ${ }^{7}$ dopaminergic neurotransmission in Parkinsonians may cause the rCBF decreases either directly via vasoconstriction linked to loss of dopamine-containing neurons or secondarily through suppression of brain tissue metabolism. Treatment with exogenous levodopa is beneficial through partial correction of dopamine depletions in striatum and probably also in other dopaminergic terminal fields such as the cortex. ${ }^{8}$ However, after several years of smooth and stable levodopa efficacy, the pattern of responsiveness often changes and becomes fluctuating. 9 At this stage, patients experi-

Address for reprint requests: Dr Eldad Melamed, Department of Neurology, Hadassah University Hospital, PO Box 12000 , Jerusalem, Israel.

Received 29 October 1985 and in revised form 14 January 1986. Accepted 17 January 1986 ence onset and termination of benefit after each single dose of levodopa (the "wearing off" phenomenon or "end of dose" akinesia). ${ }^{9}$ Such dose-related "on" and "off" response fluctuations are, in all likelihood, due to an alternating enhanced and suppressed dopaminergic transmission in the brain. ${ }^{910}$ Consequently, if $\mathrm{rCBF}$ reductions are due to decreased dopaminergic function, they should be more pronounced during the "off" stage and reversed, or at least partially corrected, during the "on" phase. We therefore measured simultaneously the rCBF and plasma levodopa levels in Parkinsonian fluctuators during the "on" and "off" response oscillations induced by individual doses of levodopa.

\section{Methods}

We studied 10 stage III-IV (according to the Hoehn and Yahr scale) patients with Parkinson's disease who were on long-term levodopa therapy (seven males and three females, aged 42 to 71, average 63 years). Average duration of illness and of levodopa treatment was 9 years (range 4 to 14) and 7 years (range 3 to 11 ), respectively. Mean total daily dose of levodopa was $1080 \pm 240 \mathrm{mg}$ (with carbidopa at a ratio of 10:1) given in 5-8 divided doses. None of these patients had overt clinical dementia. All patients had easily identifiable, marked and rather abrupt, frequent clinical fluctuations throughout the day with "off" periods of severe akinesia alternating with "on" periods of facilitated and sometimes 


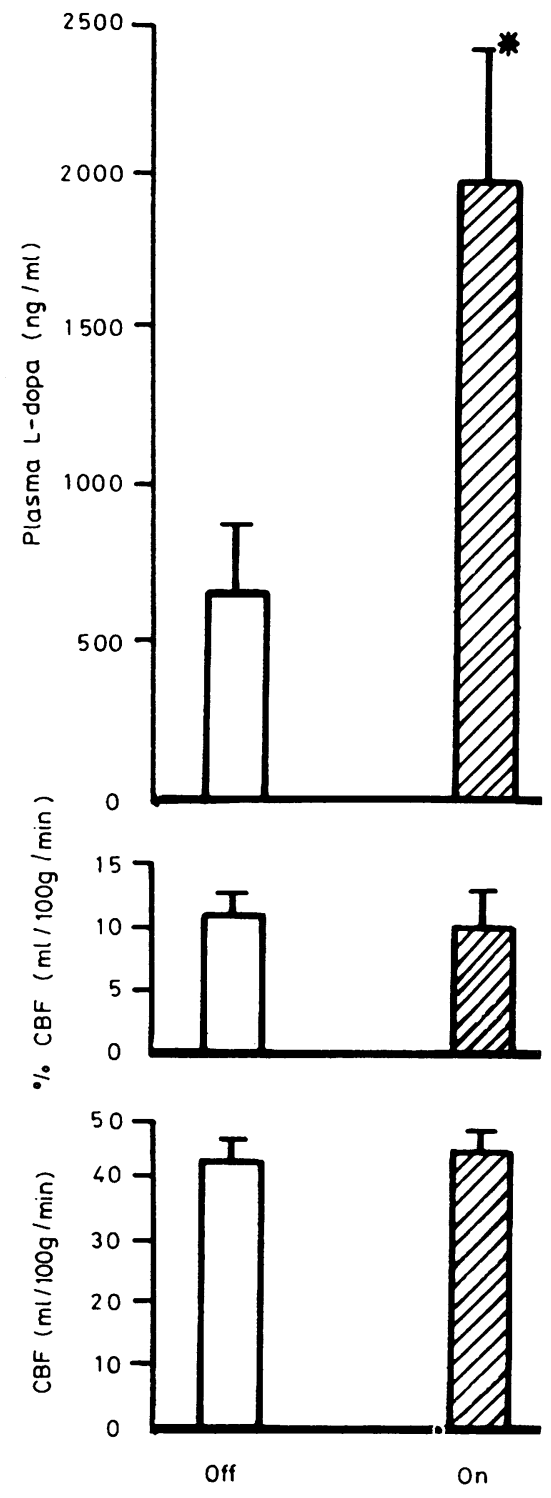

Fig Mean brain $\mathrm{CBF}, \% \mathrm{CBF}$ reduction from expected agematched normal control values and plasma levodopa levels in 10 Parkinsonians on chronic levodopa therapy with doserelated response fluctuations, during the "off" phase and at the peak of an "on" phase induced by ingestions of a single dose of levodopa (125 to $250 \mathrm{mg}$ with carbidopa at a ratio of 10:1). Mean brain $C B F$ was calculated from $C C B F$ values measured from 16 regions in both cerebral hemispheres. Expected agematched normative data were calculated in each patient from a regression line through flow values obtained in 50 normal subjects plotted against age. Columns and bars represent means $\pm S E M$ *significantly higher than in the "off" phase ( $p$ $<0.001$; t test). even nearly normal motor function often with dyskinesias. These response fluctuations were dominated by the daily schedule of levodopa and clearly linked to ingestion of single doses of the drug. Each patient underwent two resting state rCBF determinations in the same session. The first rCBF measurement was performed during an "off" phase before the next scheduled dose of levodopa. The patient then ingested his usual dose of levodopa (125 to $250 \mathrm{mg}$ with carbidopa at a ratio of 10:1) and if dose intake elicited a successful beneficial effect, the study was repeated at the peak of the "on" phase. rCBF was determined using the ${ }^{133}$ Xenon inhalation technique. ${ }^{11}$ The clearance of the radioisotope from the brain was monitored by $16 \mathrm{NaI}$ collimated scintillation detectors arranged perpendicularly over homologous regions in both hemispheres ( 8 probes over each). The rCBF was computed according to Risberg et $_{\text {al }}{ }^{12}$ as the initial slope index which represents mainly blood flow in cortical gray matter. Since rCBF declines during normal aging, ${ }^{13}$ the flow values were compared with those obtained in 50 age-matched neurologically and mentally normal control subjects. During each rCBF study, venous blood samples were drawn for later measurement of plasma levodopa levels using high performance liquid chromatography with electrochemical detection. ${ }^{14}$

\section{Results}

During the "off" phase, mean brain rCBF in the 10 Parkinsonians was significantly lower as compared with expected age-matched control values $(\mathbf{p}<0.00 \mathrm{i}$; fig). The degree of rCBF reduction was similar in the right and left hemispheres (table) and in the various brain regions. The severity of flow decreases was similar to that observed in our study of a larger $(n=110)$ population of patients with Parkinson's disease. ${ }^{2}$ Plasma levodopa levels increased by about threefold during the "on" phase induced by an ingestion of a single oral dose of levodopa (fig; table). However, mean brain CBF and the degree of its reduction from age-matched controls were unchanged as compared with those in the "off" phase (fig). Likewise, no changes were induced by levodopa during the "on" phase in right and left mean hemispheric CBF (table) and in the regional flow values. Smaller or larger single doses of levodopa (125 to $250 \mathrm{mg}$ with carbidopa) had no effect on flow parameters.

\section{Discussion}

Dose-related “on-off" response fluctuations in Parkinsonians under chronic levodopa therapy may be due to emergence of oscillations in synthesis, storage and release of dopamine from exogenous levodopa associated with disease progression, in sensitivity of the postsynaptic dopamine receptors and even in levodopa absorption from the gut. ${ }^{91015}$ It is feasible that in an "on" phase induced by a successful dose of levodopa, there is a shift from suppressed to enhanced 
Table Right and left mean hemispheric CBF and Plasma levodopa levels during levodopa-induced "off" and "on" response fuctuations in 10 patients with Parkinson's disease

\begin{tabular}{|c|c|c|c|c|c|c|}
\hline \multirow[t]{2}{*}{ Case No } & \multicolumn{2}{|c|}{$\begin{array}{l}\text { Rt hemispheric CBF } \\
\mathrm{ml} / 100 \mathrm{~g} / \mathrm{min}\end{array}$} & \multicolumn{2}{|c|}{$\begin{array}{l}\text { Lt hemispheric CBF } \\
\mathrm{ml} / 100 \mathrm{~g} / \mathrm{min}\end{array}$} & \multicolumn{2}{|c|}{$\begin{array}{l}\text { Plasma levodopa } \\
\mathrm{ng} / \mathrm{ml}\end{array}$} \\
\hline & off & On & off & On & off & On \\
\hline $\begin{array}{l}1 \\
2 \\
3 \\
4 \\
5 \\
6 \\
7 \\
8 \\
9 \\
10 \\
\text { Mean } \pm \text { SEM } \\
\text { Controls* }\end{array}$ & $\begin{array}{l}48 \cdot 3 \\
42 \cdot 7 \\
42 \cdot 0 \\
39 \cdot 6 \\
32 \cdot 8 \\
48 \cdot 0 \\
51.9 \\
45 \cdot 8 \\
38.6 \\
42 \cdot 5 \\
43 \cdot 2 \pm 1 \cdot 7 \\
48.9 \pm 1.0\end{array}$ & $\begin{array}{l}48 \cdot 2 \\
54 \cdot 1 \\
39 \cdot 0 \\
38 \cdot 1 \\
40 \cdot 4 \\
41 \cdot 3 \\
53 \cdot 3 \\
45 \cdot 0 \\
40 \cdot 3 \\
40 \cdot 6 \\
44 \cdot 0 \pm 1 \cdot 8\end{array}$ & $\begin{array}{l}50 \cdot 1 \\
39 \cdot 9 \\
43 \cdot 0 \\
44 \cdot 4 \\
32 \cdot 5 \\
43 \cdot 3 \\
54 \cdot 6 \\
44 \cdot 0 \\
39 \cdot 1 \\
43 \cdot 2 \\
43 \cdot 4 \pm 1.9 \\
49 \cdot 5 \pm 0.9\end{array}$ & $\begin{array}{l}51 \cdot 1 \\
47 \cdot 3 \\
37 \cdot 3 \\
42 \cdot 2 \\
38 \cdot 5 \\
39 \cdot 1 \\
51 \cdot 7 \\
45 \cdot 2 \\
42 \cdot 1 \\
41 \cdot 5 \\
43 \cdot 6 \pm 1 \cdot 9\end{array}$ & $\begin{array}{r}523 \\
698 \\
210 \\
475 \\
640 \\
250 \\
725 \\
1288 \\
976 \\
854 \\
664 \pm 103\end{array}$ & $\begin{array}{l}1447 \\
1458 \\
1205 \\
2200 \\
2312 \\
1404 \\
2750 \\
2586 \\
1759 \\
2195 \\
1932 \pm 172\end{array}$ \\
\hline
\end{tabular}

*Calculated from data obtained in 50 age-matched normal subjects; right and left mean hemispheric CBF values were significantly lower than those in controls ( $\mathrm{p}<0.01 ; t$ test).

dopaminergic transmission in brain. There is a rough correlation between the clinical state and plasma levodopa levels in Parkinsonian fluctuators. ${ }^{15}$ Our study shows that despite marked elevations in plasma concentrations of levodopa and presumed accelerated central dopaminergic function during the "on" phase, the $\mathrm{rCBF}$ and the severity of $\mathrm{rCBF}$ reduction from normal age-matched control values remained unaltered and similar to those in the "off" period. Initial slope index values measured by the xenon inhalation technique predominantly represent blood flow in cortical gray matter. ${ }^{12}$ Using positron emission tomography (PET), Leenders et al ${ }^{16}$ found an increase in cortical blood flow an hour after acute and very large doses of levodopa and carbidopa in patients with Parkinson's disease who were previously taken off the drug for a period of five days. No significant change was observed in volunteers given acute levodopa orally. Furthermore, when the Parkinsonians were rescanned after several weeks of continuous levodopa treatment, rCBF values in cortex were no longer elevated and returned to the baseline levels. ${ }^{16}$ In another PET study, Perlmutter and Raichle $^{17}$ found, as we did, no changes in cortical rCBF after an oral dose of levodopa in 11 nonfluctuating patients with stage I-II Parkinson's disease in whom levodopa was withdrawn for 24 hours prior to testing. Our study was different in its design using a test-retest paradigm in Parkinsonian fluctuators, within a brief time span, in a stable environment, without prior discontinuation of levodopa, before and after drug ingestion, during a baseline "off" state and again when the usual dose of levodopa had clearly produced a beneficial "on" effect. In another study we found that the rCBF was similar in Parkinsonians on levodopa and in those not treated with this drug. ${ }^{2}$ There was also no correlation between $\mathrm{CCBF}$ reduction and the total daily dosage of levodopa. ${ }^{2}$ The
rCBF was unchanged in 26 de novo patients before initiation of levodopa and eight weeks later although all responded favourably. ${ }^{18}$ Likewise, rCBF was unaltered in 14 Parkinsonians on long-term levodopa therapy 7 days after drug discontinuation and at 4 weeks after its readministration when previous beneficial effect was regained. ${ }^{2}$ Taken together, all these data suggest that treatment with levodopa does not affect the rCBF in Parkinson's disease. We did not find any correlation between the severity (stage), duration and progression of the illness and the magnitude of rCBF decreases. ${ }^{12}$ Furthermore, in patients with predominantly unilateral Parkinsonian symptomatology due to more pronounced dopamine depletions in the contralateral hemisphere, the extent of $\mathrm{rCBF}$ reductions was similar in the two cerebral hemispheres. ${ }^{12}$ These findings, combined with lack of levodopa effect suggest that reduction of the $\mathrm{rCBF}$ in Parkinson's disease is probably not due to deficient dopaminergic transmission in the brain. Use of the bidimensional xenon inhalation technique does not provide information on possible flow changes in the deeply-seated basal ganglia. However, using PET scanning, Wolfson et al ${ }^{19}$ showed that levodopa treatment does not affect the rCBF also in the caudate and putamen. This suggests that beneficial effect of levodopa in Parkinson's disease is due to improvement in dopaminergic neurotransmission and not to enhancement of $\mathrm{rCBF}$ in the basal ganglia. It also rules out the theoretical possibility that fluctuating responses to levodopa might be due to reduced circulation and diminished precursor delivery in the corpus striatum induced by long-term levodopa therapy.

We are grateful to S. Alpern and A. Uzzan for skilled technical assistance. This work was supported, in part, by the Jacob and Hilda Blaudstein Foundation 
Inc, The Israel Institute for Psychobiology, Charles E. Smith Family Foundation and the Pinchas Sapir Fund, The National Lottery of Israel.

\section{References}

${ }^{1}$ Lavy S, Melamed E, Cooper G, Bentin S. Regional cerebral blood flow in patients with Parkinson's disease. Arch Neurol 1979;36:344-8.

${ }^{2}$ Melamed E, Globus M, Mildworf B. The regional cerebral blood flow in dementing disorders. In: Fisher E, ed. Basic and Therapeutic Strategies in Alzheimer's and other Age-Related Neuropsychiatric Disorders. New York: Plenum Press, (in press.)

${ }^{3}$ Edvinsson L, Hardebo JE, McCulloch J, Owman CH. Effects of dopaminergic agonists and antagonists on isolated cerebral blood vessels. Acta Physiol Scand 1978;104:349-59.

${ }^{4}$ Ingvar M, Lindvall O, Stenevi U. Apomorphine induced changes in local cerebral blood flow in normal rats and after lesions of the dopaminergic nigrostriatal bundle. Brain Res 1983;262:259-69.

${ }^{5}$ Lavyne MH, Wurtman RJ, Moskowitz MA. Brain catecholamines and cerebral blood flow. Life Sci 1975;16:475-86.

${ }^{6}$ Harik SI, LaManna JC, Synder S, Wetherbee JR, Rosenthal M. Abnormalities of cerebral oxidative metabolism in animal models of Parkinson disease. Neurology 1982;32:382-9.

${ }^{7}$ Javoy-Agid F, Agid Y. Is the mesocortical dopaminergic system involved in Parkinson's disease? Neurology 1980;30:1326-30.

${ }^{8}$ Globus M, Melamed E. Is exogenous L-dopa utilized differently in rat nigrostriatal, nigromesolimbic and nigromesocortical dopaminergic neurons? Neurology 1985;35 (suppl 1):159.
${ }^{9}$ Marsden CD, Parkes JD, Quinn N. Fluctuations of disability in Parkinson's disease-clinical aspects. In: Marsden CD, Fahn S, eds. Movement Disorders, London: Butterworth, 1983:96-122.

${ }^{10}$ Lewitt P, Chase TN. “On-off” effects: the new challenge in Parkinsonism. Trends Neurosci 1983;6:1-4.

${ }^{11}$ Obrist WD, Thompson HK, Wang HS, King $\mathrm{CH}$. Regional cerebral blood flow estimated by 133 Xenon inhalation. Stroke 1975;6:245-56.

${ }^{12}$ Risberg J, Ali Z, Wilson EM. Regional cerebral blood flow by 133 Xenon inhalation: preliminary evaluation of an initial slope index in patients with unstable flow compartments. Stroke 1975;6:142-8.

${ }^{13}$ Melamed E, Lavy S, Bentin S, Cooper G. Reduction in regional cerebral blood flow during normal aging in man. Stroke 1975;11:31-5.

${ }^{14}$ Hefti F, Melamed E, Wurtman RJ. The site of dopamine formation in rat striatum after L-dopa administration. J Pharmacol Exp Ther 1981;217:189-97.

${ }^{15}$ Nutt JG, Woodward WR, Hammerstad JP. The "on-off" phenomenon in Parkinson's disease. Relation to levodopa absorption and transport. $N$ Eng $J$ Med 1984;310:483-8.

${ }^{16}$ Leenders KL, Wolfson L, Gibbs JM, Wise RJS, Causon $R$, Jones T, Legg NJ. The effects of levodopa on regional cerebral blood flow and oxygen metabolism in patients with Parkinson's disease. Brain 1985;108:171-91.

${ }^{17}$ Permutter JS, Raichle ME. Regional blood flow in hemiparkinsonism. Neurology 1985;35:1127-34.

${ }^{18}$ Melamed E, Lavy S, Cooper G, Bentin S. Regional cerebral blood flow: measurement before and after levodopa. J Neurol Sci 1978;38:391-7.

${ }^{19}$ Wolfson LI, Leenders KL, Brown LL, Jones T. Alterations of regional cerebral blood flow and oxygen metabolism in Parkinson's disease. Neurology 1985;35:1399-405. 